\title{
Carmen Miranda e nacionalismo na década de 1930
}

\author{
Carmen Miranda and nationalism in 1930's
}

por Káritha Bernardo de Macedo

\section{RESUMO}

Na década de 1930, a música foi um dos grandes vetores na articulação de uma identidade nacional e, nesse universo, Carmen Miranda consagrou-se como cantora de sucesso, especialmente pela participação em rádio. Assim, o objetivo deste trabalho é estabelecer algumas relações entre Carmen Miranda, sua imagem e canções interpretadas por ela, e um projeto político de nação, ligado à rádio e à canção popular por meio de um estudo histórico. Dentro de um contexto de exacerbação de nacionalismos, Carmen passou a integrar um discurso de identidade nacional, contribuiu com o "branqueamento" do samba e legitimou sua ascensão e consagração como canção nacional.

Palavras-chave Carmen Miranda; samba; identidade nacional; nacionalismo

ABSTRACT

In the 1930's music was one of the major vectors in the articulation of a national identity, in this context Carmen Miranda established herself as a successful singer especially for her work in the radio. Thus, this paper intent to establish some relations between Carmen Miranda, her image and songs performed by her and a political project of nation, associated to radio and popular music through a historical study. In a time of nationalism exacerbation, she became part of the national identity discourse, contributed to the "whitening" of samba and to its rise and recognition as the national music.

Keywords Carmen Miranda; samba; national identity; nationalism 
Carmen Miranda nasceu Maria do Carmo Miranda da Cunha, em 9 de fevereiro de 1909, em Portugal, mas logo ganhou de seu tio materno o apelido de Carmen, por lembrar uma espanhola tal qual a popular personagem da ópera de Bizet ${ }^{1}$. Aportou no Brasil junto à sua família antes mesmo de completar um ano de idade. Na cidade do Rio de Janeiro, nasceram seus irmãos, seu pai se estabeleceu como barbeiro, e a família montou uma pensão na Travessa do Comércio. Esta, por sua vez, era frequentada por vários músicos, como Pixinguinha e seus amigos, cuja atmosfera contribuiu para 0 gosto de Carmen pela música (MENDONÇA, 1999, p. 40-42). A carreira profissional de Carmen começou no final de 1929 com o auxílio de Josué de Barros, quando esse conseguiu que a Brunswick gravasse um disco de Carmen. Porém, insatisfeitos com a gravadora, a dupla foi atrás da Victor, estadunidense recém-estabelecida no Brasil, que fechou novo contrato. Em 1930, foi lançada, em pleno Carnaval, a canção "Tahí, que fez de Carmen um sucesso (CASTRO, 2005, p. 45-48; 52).

Logo, a Victor fechou um contrato para Carmen gravar mais catorze discos, cerca de um disco a cada dezoito dias (CASTRO, 2005, p. 60; KERBER, 2002, p. 01). Contudo, uma das exigências era gravar apenas músicas brasileiras e tentar ao máximo omitir sua origem portuguesa. Mesmo sem os tangos tradicionais de seu repertório, a cantora agradou os ouvintes e se sentiu à vontade para dispensar os conselhos da gravadora, revelando sua identidade em uma entrevista (GARCIA, 2004, p.33). Quando Ihe perguntaram se era nascida no Rio mesmo, Carmen respondeu:

'Todos que me conhecem pensam que sou brasileira, nascida no Rio. Como se vê, sou morena e tenho o tipo da brasileira. Mas sou filha de Portugal. Nasci em marco de Canavazes e vim para o Brasil com um ano de idade [na verdade menos]. Mas meu coração é brasileiro e, se assim não fosse, eu não compreenderia tão bem a música desta maravilhosa e encantadora terra' (CARMEN apud CASTRO, 2005, p. 63, grifo nosso).

\section{Pertencendo a uma nação}

No Brasil, o início do século XX foi caracterizado por transformações econômicas e sociais, com a crise da bolsa de valores de Nova Iorque em 1929, e o Brasil, que tinha como base econômica a agro-exportação, sofreu muitas perdas. Um dos setores mais prejudicado foi o cafeeiro, consequentemente minando os ideais de sua oligarquia que estava diretamente ligada ao governo do país (política do "café com leite") 2 (TRONCA, 1993, p. 08-15, 37; KERBER, 2002, p.48; D'ARAUJ0, 2000, p. 41). Perante a crise internacional que se formava, muitos países buscaram a

1 Carmen, uma ópera do compositor francês Georges Bizet, é uma das quatro óperas mais famosas do século XIX. Ver: PELS; CRÉBAS, 1992; MCCLARY, 1998.

2 Ver: BORGES, 1979. 
autossuficiência como forma de se proteger. Com o poder hegemônico no cenário político brasileiro abalado, as condições se mostraram propícias ao assentamento de discursos nacionalistas. No Brasil, o primeiro passo foi dado com a Revolução de 1930, em que Getúlio Vargas assumiu interinamente a presidência do país com 0 apoio do Exército.

Os nacionalistas apostavam na recuperação do país a partir de seu desenvolvimento e aproveitamento de suas riquezas naturais, incluso, neste último, o cidadão nacional. Isso se daria com a unificação nacional, adequação da cultura e das instituições à realidade brasileira e a ampla utilização dos recursos nacionais para um desenvolvimento autodeterminado. Assim, durante a década de 1930, nota-se um grande incentivo do governo à industrialização e modernização do país. Era tempo de afirmação nacional e de um novo projeto de nação (OLIVEIRA, 1990, p. 29; GARCIA, 2005, p. 95; MENDONÇA, 1999, p. 26).

Dentro desse contexto que se formava, para amenizar a nacionalidade portuguesa de Carmen, foi encomendada à Randoval Montenegro (1930) a canção “Eu gosto da minha terra", que pode ser considerada uma precursora dos sambas de exaltação³.

Deste Brasil tão famoso eu filha sou, vivo feliz/ Tenho orgulho da raça, da gente pura do meu país/ Sou brasileira reparem, no meu olhar, que ele diz/ E o meu sambar denuncia que eu filha sou deste país/ Sou brasileira, tenho feitiço/ Gosto do samba, nasci p'ra isso/ o 'fox trot' não se compara/ Com o nosso samba, que é coisa rara/ Eu sei dizer como ninguém/ Toda a beleza que o samba tem/Sou brasileira, vivo feliz/ Gosto das coisas do meu país/ Eu gosto da minha terra e quero sempre viver aqui/Ver o Cruzeiro tão lindo do céu da terra onde eu nasci/ Lá fora descompassado o samba perde o valor/Que eu fique na minha terra permita Deus, Nosso Senhor [sic] (RANDOVAL MONTENEGRO, 1930).

Contudo, pouca importância se dava ao nascimento português de Carmen Miranda, visto que os jornais e as revistas não se constrangiam em chamá-la de "rainha do disco", "a maior expressão da música brasileira" e "Ditadora Risonha do Samba" (CASTRO, 2005, p. 62; MENDONÇA, 1999, p. 26).

De todo modo, a portuguesa mais brasileira que muitos brasileiros indubitavelmente não era o único estrangeirismo em voga nem o primeiro a ser nacionalizado. As próprias marchinhas que cantavam nasceram como adaptações de marchas portuguesas e do ragtime estadunidense, que fizeram sucesso apenas quando tocadas dentro do formato das jazz-bands nos bailes de carnaval (TINHORÃO, 1991, p.126). Além do formato e do visual dos músicos, as marchinhas adotaram dos Estados Unidos também o "tempo quebrado e acelerado dos fox-trots e charlestons"

3 Sambas que seguiam uma fórmula de elogio exacerbado à nação e ao estilo samba-canção que eram incentivados pelo Estado Novo. "Aquarela do Brasil" (1939) foi considerada a pioneira do gênero. 
(TINHORÃO apud GARCIA, 2004, p. 34). Na verdade, com o início dos anos 1930 e a Política da Boa Vizinhança, selada em 1933, começou a entrada em larga escala da influência desse país; filmes, gírias, aparelhos, tecnologia e investimentos.

Foi nesse contexto que os brasileiros aprenderam a substituir os sucos de frutas tropicais onipresentes à mesa por uma bebida de gosto estranho $e$ artificial chamada Coca-Cola. Começaram também a trocar sorvetes feitos em pequenas sorveterias por um sucedâneo industrial chamado Kibon, produzido por uma companhia que se deslocara às pressas da Ásia, por efeito da guerra. Aprenderam a mascar uma goma elástica chamada chiclets e incorporaram novas palavras que foram integradas à sua lingua escrita. Passaram a ouvir o fox-trot, o jazz e o boogie-woogie, entre outros ritmos, e assistiam agora a muito mais filmes produzidos em Hollywood (MOURA, 1988, p. 7-12, apud MAUD, 2005, p. 49).

Derradeiramente, seria a Política da Boa Vizinhança que levaria Carmen Miranda aos Estados Unidos em 1939.

Em face de tantas mudanças e da ascensão de Estados nacionalistas globalmente, o novo poder hegemônico tinha a necessidade de reestruturar à imagem que se tinha de Estado brasileiro e impunha a noção que o "pertencimento" a ele é um dever, ao passo que criava uma comunidade cultural e a protegia contra a globalização. Partindo desse ideal, iniciou-se um processo de vivificação de uma identidade nacional por meio de narrativas performáticas, criando ícones e mitos, recontando a história, "reconstruindo" o presente e, por fim, disseminando os ideais do poder vigente e articulando a mimese social desses discursos (BHABHA, 1998).

Carmen Miranda coloca-se justamente dentro desse projeto, figurando o preceito de que só "nacional é popular" (SODRÉ apud ORTIZ, 1994, p.127). A fim de se atingir a função integradora e disciplinadora concomitantemente, Carmen está dentro de um discurso densamente sedutor, no qual representa a popularização dos ideais governistas e alimenta a imagem do "tipo brasileiro" (como ela mesma se autodenominou), o que significava traçar uma fronteira entre o certo e o errado, entre o natural e o excluído, ao mesmo tempo em que se quebrava com os significados pré-estabelecidos sobre o cidadão brasileiro e como estavam embutidos no contexto social (BAUMAN, 2005, p. 21-28). Carmen Miranda foi apenas um dos artifícios de uma política de unificação e identificação nacional, cujo percurso é narrado por várias vozes.

\section{A rádio com uma rainha e um rei}

Carmen era bastante atenta às evoluções tecnológicas da rádio e das gravações de discos e ao que mais envolvesse seu ofício. Por isso mesmo, ao lado de seu amigo Mário Reis, foi uma das poucas a dominar o microfone de um modo que seria padrão somente vinte anos depois (GATTI, 2006, p. 95). Tal habilidade interpretativa 
fez com que a revista Phonoarte afirmasse que era "senhora [...] dos segredos do microfone e a Victor [gravadora] tem nela um dos maiores fatores para o sucesso de seus discos populares" (MENDONÇA, 1999, p. 28). Muitos compositores escreviam especialmente para Carmen, pois, com sua interpretação única, fazia de qualquer música um sucesso e significava uma redenção da profissão, que ainda não era bem vista pela sociedade, o que levou Teófilo de Barros a comentar que "se Carmen gravar uma música qualquer horrorosa, essa música se vende aos miIheiros, é tocada, cantada, assobiada até azedar e encher de dinheiro as editoras. 0 compositor pode ser até qualquer um. Não tem importância. Ficará importante do dia para a noite" (autor??? apud KERBER, 2007, p.14).

Daí em diante, Carmen passou a ser convidada de honra de muitos eventos, solicitada em tardes de arte, eventos de samba e violão, festivais, festas e até mesmo para inaugurações, como a da piscina do clube do Fluminense. Assim, havia se tornado uma figura muito cativante e sua presença parecia refletir a unidade de toda a cidade. Era o símbolo que queriam do Rio de Janeiro (CASTRO, 2005, p. 61).

Em 1931, juntamente com Chico Alves e Mario Reis, foi contratada por um empresário argentino para uma temporada de um mês de música brasileira em Buenos Aires. Era o começo de uma carreira internacional em uma cidade muito mais fervilhante em artes que o próprio Rio de Janeiro. Daí em diante passou a fazer temporadas anuais na Argentina, e seu repertório era direcionado ao novo público, com canções cuja proposta era justamente seduzir com elogios também aquela terra (CASTRO, 2005, p. 70; KERBER, 2002, p. 36-37). 0 sucesso internacional possivelmente contribuiu para o enaltecimento da artista como representante da cultura brasileira, pois o reconhecimento estrangeiro atuava como a legitimação de uma diferença que caracterizava os brasileiros como únicos.

Nesse mesmo ano (1931), Getúlio Vargas assumiu o governo interinamente e, ao modificar drasticamente a estrutura da rádio dando-lhe um formato mais popular, pois até então a programação era voltada apenas para um público da elite, com músicas eruditas, conferências e palestras, consequentemente impulsionou a carreira de Carmen. Uma vez que a rádio era um veículo que transmitia informações com alta velocidade e atingia uma grande massa que não sabia ler jornais, percebeu-se nesse veículo um grande potencial para propaganda política e disseminação de ideologias. Getúlio Vargas divulgava abertamente o potencial da rádio na unificação do país e no entrelaçamento "dos diversos interesses da nação". Em 1937, pronunciou:

o Governo da União procurará entender-se a propósito com os estados e municípios, de modo que,, mesmo nas pequenas aglomerações, sejam instalados aparelhos rádio-receptores, providos de alto-falantes, em condições de facilitar a todos os brasileiros (...) toda sorte de notícias tendentes a entrelaçar os interesses diversos da nação (AUTOR??? apud VIANNA, 2004, p. 110).

Com o decreto n. 21.111, de 1ć março de 1931, estabeleceu-se que a rádio seria um 
serviço público com publicidade legalizada. Desse modo, a partir do momento em que se abriu a possibilidade de lucrar financeiramente com a rádio e ainda com certo incentivo do Estado, o setor começou a se especializar. De 1932 a 1937, foram instaladas 42 novas estações de rádio, sendo que, em 1937, existiam 63 estações, passando para 106 em 1944 e 111 em 1945. As rádios começaram a competir pelas melhores atrações, e Carmen despontou como cantora, ganhou um programa semanal na Mayrink Veiga ${ }^{4}$, tornou-se a voz da vinheta dessa estação de rádio e ganhou um aumento considerável no assédio e no salário (GARCIA, 2005, p. 145-146; GARCIA, 2004, p. 81-82). Sua participação na rádio agora valia cinquenta mil réis, o maior cachê da praça (CASTR0, 2005, p. 61). Contudo, era festejada não apenas por seu talento cativante, mas também porque era um outdoor ambulante da proposta de mulher brasileira e de nação unida que se queria transmitir. Carmen era portuguesa, mas dizia: “'Olhem para mim e vejam se não tenho o Brasil em cada curva do meu corpo'” (AUTOR??? apud VIANNA, 2004, p.130).

Antes de ser a baiana, sua imagem pública e as narrativas de suas canções traziam o modelo de uma mulher bem-sucedida, batalhadora, bela, sedutora e tinha graça e bom humor até nas adversidades. Na música "As cantoras da rádio", mais que um hino à popularidade da rádio, essas mulheres que cantavam e embalavam o sono $\mathrm{e}$ o amanhecer eram as matriarcas que uniam a nação de norte a sul (CAPELATO, 1999, p.176). Mareia Rivera (2000, p. 61; 65) salienta que a música popular brasileira:

Como manifestação feita de elementos diversos através de novos processos de síntese, [...] era considerada como espelho e anúncio da formação das novas 'raças', ao mesmo tempo que sua modernidade baseada em fontes tradicionais servia como exemplo, arauto ou promessa do ideal de uma civilização própria [...] esboço de um indivíduo em sintonia com o meio tropical, que funciona como representação do nacional perante o estrangeiro.

Esse era mesmo um dos objetivos da rádio, tanto que, no Brasil, ela nasceu na década de 1930 já sob controle estatal. Entretanto, havia sobre ela uma vertente que se pautava pelo consumo e outra que pré-anunciava o Estado-Novo, entendendo a rádio como um instrumento educativo, formador da consciência nacional e indispensável à integração nacional. 0 projeto era chamado de "integração nacional pelas ondas" (CAPELATO, 1999, p. 177) que, por meio das canções e narrativas emitidas, se propunha a homogeneizar o povo e o caráter da nação, com metáforas da fecundidade vegetal, da variedade de alimentos e de elementos tropicais, como sol, calor, mar e barro, que sustentariam a formação desses indivíduos e os integrariam como oriundos daquela natureza (RIVERA, 2000, p. 64). José Murilo de Carvalho atesta que houve um esforço em definir também a psicologia do homem brasileiro, narrado a partir de então como pessoa fraternal, cooperadora, generosa,

4 A rádio mais ouvida até a década de 1940 e que depois passou a ser sua gravadora. Depois desse período, perdeu seu posto para a Rádio Nacional (MENDONÇA, 1999, p. 30). 
cordial, familiar ao mesmo tempo em que é honesta e trabalhadora. Para esse autor, não era compatível com essa visão acentuar os conflitos raciais e, nas relações de trabalho, tudo deveria se resolver pela cooperação e pelo entendimento (CARVALHO, 1998, p. 262). Um interessante exemplo é esta notícia da revista 0 Cruzeiro de 21 de outubro 1933:

As duas irmãs têm [sic] poderes [...] para cantar os nossos sambas. E nossas marchinhas. Músicas que são bem a fotografia [sic] da nossa alma. De povo novo. A quem está traçado um destino grandioso. $\mathrm{Na}$ história da humanidade. [...] as irmãs Miranda impuseram-se a admiração do nosso paiz [sic] [...] sabem cantar o que é nosso(o Cruzeiro, Apud GARCIA, 2004, p. 38).

Do ano da notícia (1933), é a canção "Tarde na Serra", de Mário Reis, interpretada pela Carmen Miranda, que destaca "Como é linda a nossa terra! Que céu de anil! Os pássaros vão em revoada saudando o Brasil [...]" (KERBER, 2002, p. 38). Essa era apenas uma das muitas que viriam, pois, com a instituição do Estado Novo, em 1937, a situação se especializaria ainda mais.

As mudanças do Estado sugeriam um novo pensar sobre a identidade nacional, condizente com a interpretação que o Estado fazia das crises e dos problemas sociais, iniciando um processo de renegociação das representações de identidades nacionais (ORTIZ, 1994, p.130). Nesse contexto, a rádio desponta como território propício, associado a outros meios de comunicação, para que artistas como Carmen se firmassem em uma projeção de sucesso. Segundo Alessander Kerber (2007, p. 14):

Alguns desses artistas, justamente por circularem entre meios culturais distintos, participaram como mediadores do processo de construção de uma nova síntese identitária nacional. [...] Como grandes ídolos populares, divulgavam idéias [sic], símbolos e estereótipos que eram consumidos por grande parte da população.

Durante a década de 1930, Carmen não era uma figura diferente das outras cantoras, apesar de sua elegância e sua preocupação com a aparência. Nesse período, o discurso de nacionalidade era pronunciado em praticamente todas as produções culturais e articulado como bem de consumo. Além de Carmen Miranda, houve uma série de outros artistas que traziam a temática da nação em suas performances. Seguramente, o carisma de Carmem e certa "malandragem" que tinha forte apelo conseguiram diferenciá-la e alavancá-la para uma carreira meteórica internacional.

\section{Samba e nacionalismo}

No universo do Estado Novo, a música popular urbana serviu como um veículo para conquistar uma larga parcela da população brasileira. Conforme Hermano Vianna (2004, p.111) e seu "Mistério do Samba", foi apenas nos anos de 1930 que 
o samba ganhou o status de símbolo nacional, relegando outros gêneros ao patamar de regionais ${ }^{5}$ (2004, p.111). Contudo, não foi sem resistências que o samba se estabeleceu., 00 fato de que boa parte dos músicos que o tocavam eram negros causava desconforto em alguns setores da sociedade brasileira. Os "0ito Batutas", grupo musical de Pixinguinha e Donga, composto sobretudo por negros, foi um dos primeiros grupos a tocar samba em grandes eventos. Todavia, entre outras "coisas brasileiras", como maxixes, lundus, corta-jaca, batuques, cateretês, eram confundidos em certa medida como manifestações quase folclóricas da cultura nacional (VIANNA, 2004, p.116). Durante a década de 1920, o grupo teve performances no elegante Cine Palais, na embaixada estadunidense, no Pavilhão da General Motors, na Bélgica, e foi financiado por Arnaldo Guinle para apresentações no Brasil e na França, que contribuíram com a valorização do samba ao mesmo tempo em que trouxeram novas referências estrangeiras para suas composições (VIANNA, 2004, p.117). Até então o samba ainda não era um gênero fixo, mas uma mistura de muitas expressões musicais, que foi inicialmente amaxixado e depois depurado em algo que se diferenciaria internacionalmente.

Daí em diante, adaptações quanto às manifestações dos elementos da cultura africana foram feitas, mesclando-se a outros gêneros e adequando cuidadosamente essa nova música aos ideais da nação. 0 samba brasileiro estava sendo remodelado a fim de se tornar um gênero musical competitivo em meio à expansão do mercado fonográfico no país, diante da presença de manifestações de outros países (RIVERA, 2000, p. 138-141). Entretanto, para isso, adequou-se aos poucos em um formato mais próximo da tradição europeia e estadunidense. Assim, ainda que fruto de origens controversas ${ }^{6}$, foi a partir do samba que os elementos afro foram redefinidos para participar da civilização da cidade (KRAUSCHE, 1983, p. 29), tornando-se também um mediador cultural entre os grupos sociais e os que defendiam como brasilidade.

No primeiro governo de Getúlio Vargas, o fortalecimento do samba como canção nacional veio juntamente com o apoio ao carnaval, e isso acontecia oficial e extraoficialmente. Em 1932, foi realizado o primeiro baile de carnaval no Teatro Municipal do Rio de Janeiro; em 1935, Villa Lobos incorporou um samba de Ernani Silva em uma apresentação de seus cantos orfeônicos; em 1935, o carnaval entrou no

50 próprio carnaval, que hoje tem o samba como ritmo que o embala por excelência, era tomado por modas musicais passageiras, e dançava-se ao som de polcas, valsas, tangos, mazurcas, charleston, fox-trot, maxixes, modas, marchas, cateretês e desafios sertanejos (VIANNA, 2004, p.111).

6 Conforme Valter Krausche, "o samba não teve uma origem pura; apesar de nascer das mãos e das vozes negras, que vinham do bairro da Saúde, [ele] incorporava traços 'estranhos' à 'cultura' do lugar, tornava-se expressão que já se endereçava a outros” (1983, p. 29). João da Baiana afirmou que o samba não veio do morro, mas da planície, e que este era apenas o esconderijo dos sambistas reprimidos pela polícia. Donga (Ernesto dos Santos) já dizia que o samba veio da Bahia, do partido-alto, com mote e glosas improvisadas, perseguido e que formava rodas de samba com sapateados, música de negros (Idem, 1983, p. 29). 
calendário oficial da prefeitura do Rio de Janeiro; em 1936, a Hora do Brasil transmitia um samba da Escola Mangueira "diretamente para a Alemanha nazista"; em 1937, o governo estabeleceu que os enredos de escolas de samba teriam "caráter histórico, didático e patriótico"; e, em 1939, na Exposição Nacional do Estado Novo organizada por Villa Lobos, houve apresentações de Francisco Alves, Patrício Teixeira, Almirante, Donga, de escolas de samba cariocas e Carmen Miranda (entre outros), e aos estrangeiros que aqui chegavam eram prontamente apresentados a feijoada e as escolas de samba (VIANNA, 2004, p.124-126). Assim, a nacionalização do samba também estava ligada a um projeto de modernização do país e a um reposicionamento internacional.

Nesse sentido, nos anos 1930 e com a cooptação do samba como símbolo nacional, o perfil dos músicos, compositores e cantores de samba mudou. Ainda se fazia música na boêmia, porém só eram considerados cenário privilegiado para as produções culturais brasileiras aqueles povoados formados principalmente por personagens estudados, geralmente assegurados pelo funcionalismo público, de situação econômica estável e fundamentalmente "brancos"; uma boemia comportada da intelectualidade, pois apresentavam uma melhor reputação aos olhos estado-novistas. 0 samba facilitava no imaginário social a ilusão da integração racial, bem como o processo de "branqueamento" pelo qual passava, e viabilizava sua aceitação como parte de um ideário que apregoava que somente uma "raça superior" poderia dar sentido à sua sonoridade, ou seja, civilizá-la (GARCIA, 2004, p. 42).

Os novos compositores profissionais da era da rádio ${ }^{7}$ criavam uma derivação própria do estilo para as orquestras de salão e com um ritmo amolengado, que soava a um bolero. Com a interferência de Pixinguinha, contratado da Victor, esse tipo de música ganhou o requinte das orquestras e veio a ser a marca registrada da rádio. Assim, após várias transformações e influências, o chamado samba urbano ou samba-canção ${ }^{8}$ passou a ser difundido pela indústria fonográfica e pela rádio como o "samba autêntico", retrato da música brasileira, gênero em que Carmen Miranda e Josué de Barros se destacavam como intérpretes (TINHORÃO, 1991, p.130; GARCIA, 2004, p.35). De fato, o processo de "branqueamento" do samba caminhou junto à ascensão de Carmen.

0 gênero alavancou quando intérpretes como Carmen Miranda, Silvio Caldas e Francisco Alves começaram a gravar seus sambas. Carmen tinha muita graça e cativava o público com performances cômicas e o governo com os elogios à nação (GARCIA, 2004, p. 43-44). Ana Rita Mendonça (1999, p.41) esclarece que "Carmen era pobre, mas moça de família - e branca. Compunha um arranjo adequado

7 Dentre os compositores profissionais, destacam-se Ari Barroso, Lamartine Babo, João de Barros, Noel Rosa, Assis Alves, Haroldo Lobo, Ataulfo Alves e outros.

80 samba-canção era apenas uma das ramificações do samba, segmentadas eminentemente por padrões socioculturais. 
para a República. (...) Coquete, a portuguesinha passava à face reformada da cidade, mais parecendo filha de burguesíssima família". Carmen Miranda, em suas canções, popularizava a nação e vivenciava as narrativas de suas canções. Dessa maneira, resumia a imagem que se queria da capital brasileira: “Rio, lindo sonho de fadas. Noites sempre estreladas e praias azuis'"'9 (Ibidem, p. 41).

Rainha branca do samba, Carmen atendia ao figurino estado-novista, num primoroso equilíbrio de opostos. Vestida elegantemente, não abria mão nem da ginga nem da gíria associadas aos moradores das favelas. Cantando a cidade, o morro e o Brasil, a moça branca colaborava para legitimar seu jeito como brasileiro (MENDONÇA, 1999, p.53).

Assim, o nome de Carmen Miranda já remetia o imaginário coletivo a uma série de características e significantes carregados pela intérprete, alterando com sua performance o sentido das canções e veiculando uma mensagem com sua trajetória particular. Em suas canções, a natureza era personificada, bem como as cidades e as grandes massas populares, pois a alma nacional era também representada pelo tipo da Pequena Notável. Contudo, a realidade era muito diferente do que propunham essas narrativas, e forjar uma identidade comum em um país com as dimensões do Brasil e tantas desigualdades sociais foi uma empreitada complexa. Dessa forma, o discurso cantado por Carmen só foi sedimentado porque era proposto por várias vozes que deram vazão a uma repetição performática dos signos nacionais selecionados, geradores de uma narrativa presente e atuante e de uma comunidade imaginada10 (BHABHA, 1998, p. 208).

\section{Considerações Finais}

Carmen Miranda teve destaque na música, nos palcos e no cinema e foi a artista (luso) brasileira que obteve maior sucesso no exterior, presente há várias décadas como símbolo de brasilidade e integrando vividamente a história brasileira. Como

9 Marcha de João de Barro (Braguinha) Primavera no Rio, interpretada por Carmen Miranda, gravado em setembro de 1934.

10 Para Benedict Anderson, a nação é uma comunidade política imaginada, limitada e soberana. Dificilmente se poderá conhecer todos os membros de uma nação e conhecer inteiramente seu território geográfico e fronteiras. Portanto, é necessário que os limites de um território sejam imaginados, e as possíveis diferenças entre os diversos membros desse espaço sejam postos de lado, a fim de que se crie uma comunidade, uma unidade. "Ela é imaginada por que nem mesmo os membros das menores nações jamais conhecerão a maioria de seus compatriotas, nem os encontrarão, nem sequer ouvirão falar deles, embora na mente de cada um esteja viva a imagem de sua comunhão" (ANDERSON, 1989, p.14). Nesse sentido, a nação é imaginada como limitada por suas fronteiras, soberana porque se sobrepõe a todos os demais poderes e, como uma comunidade "porque, sem considerar a desigualdade e exploração que atualmente prevalecem em todas elas, a nação é sempre concebida como um companheirismo profundo e horizontal" (ANDERSON, 1989, p.15-16). 
artista, em seu tempo integrou simbolicamente parte das narrativas que deram origem a um imaginário e a uma representação da nação brasileira. Durante a década de 1930, Carmen pronunciava em suas canções e em sua performance um discurso de nacionalidade, de elogio ao Brasil, às suas riquezas naturais e a seu povo.

Portanto, seu papel ultrapassava a bela voz e o requebrado, e a baiana criada apenas em 1939 ficou famosa pelos filmes hollywoodianos. A figura que hoje se conhece como Carmen Miranda foi de fato o produto de uma série de fatores, que narra, por um viés diferenciado, a história brasileira como nação por meio de sua arte. 


\section{Referências}

> ANDERSON, Benedict. Nação e consciência nacional. São Paulo: Ática, 1989.

> BAUMAN, Zygmunt. Identidade: entrevista a Benedetto Vecchi. Rio de Janeiro: J. Zahar, 2005.

> BHABHA, Homi K. O Local da Cultura. Belo Horizonte. Ed. Da UFMG, 1998.

> CAPELATO, Maria Helena. Propaganda política e controle dos meios de comunicação. In: PANDOLFI, Dulce (organizadora). Repensando o Estado Novo. Rio de Janeiro: Ed.Fundação Getulio Vargas, 1999. P.167-178.

> CARVALHO, José Murilo. Brasil: nações imaginadas. In Pontos e bordados: escritos de história e política. Belo Horizonte: UFMG, 1998.p.233-289.

> CASTRO, Ruy. Carmen: uma biografia. São Paulo: Companhia das Letras, 2005.

> D’ARAUJ0, Maria Celina. 0 Estado Novo. Rio de Janeiro: Jorge Zahar, 2000.

$>$ GARCIA, Nelson Jahar. Estado Novo. Ideologia e propaganda política. São Paulo: Loyola, 2005.

> GARCIA, Tânia da Costa. 0 "it" verde e amarelo de Carmen Miranda. São Paulo: AnnaBlume; Fapesp, 2004.

> GATTI, José. Carmen Miranda's white dress: ethnicity, syncretism and subaltern sexualities in springtime in the rockies. In Revista llha do Desterro. A Journal of English Language, Literatures in English and Cultural Studies. Brasil, Florianópolis: UFSC. n.51, 2006. P.93-108. ISSN $-2175-8026$.

$>$ KEACH, William. Apresentação. In. TROTSKY, Leon. Literatura e revolução. Jorge Zahar Editor: Rio de Janeiro, 2007. P.7-20.

> KERBER, Alessander. 0 que é que a bahiana tem? Representações da Nação Brasileira nas Canções Interpretadas por Carmen Miranda na Década de 30. Dissertação (Mestrado em História) - Universidade do Vale do Rio dos Sinos -UNISINOS. Programa de Pós-Graduação em História. São Leopoldo, 2002. 155 p.

> KERBER, Alessander. Representações das identidades nacionais argentina e brasileira nas canções interpretadas por Carlos Gardel e Carmen Miranda (19171940). Tese (Doutoramento em História) - Universidade Federal do Rio Grande do Sul - UFGRS. Instituto de Filosofia e Ciências Humanas. Programa de Pós-Graduação em História. Porto Alegre, 2007. 311 p.

> KRAUSCHE, Valter. Música popular brasileira. Brasiliense: São Paulo, 1983.

> MAUAD, Ana Maria. Genevieve Naylor, fotógrafa: impressões de viagem (Brasil, 1941-1942). In Revista Brasileira de História. São Paulo, v. 25, nć 49, junho de 2005.

> MENDONÇA, Ana Rita. Carmen Miranda foi a Washington. Rio de Janeiro: Record, 1999.

> OLIVEIRA, Lúcia Lippi. A questão nacional na Primeira República. São Paulo:

Brasiliense; Brasília: CNPq, 1990. 
> ORTIZ, Renato. Cultura brasileira e identidade nacional. São Paulo: Brasiliense, 1994.

> RIVERA, Mareia Quintero. A cor e o som da nação, a idéia de mestiçagem na crítica musical do caribe hispânico e do Brasil (1928-1948). São Paulo: Annablume Editora, 2000.

> TINHORÃO, José Ramos. Pequena história da música popular: da modinha à lambada. 6ed. Art Editora: São Paulo, 1991.

> TRONCA, Ítalo. Revolução de 30: a dominação oculta. 8. ed. São Paulo: Brasiliense, 1993.

> VIANNA, Hermano. 0 mistério do samba. 5. ed. Rio de Janeiro: J. Zahar: Ed. da UFRJ, 2004.

Káritha Bernardo de Macedo, mestranda do Programa de Pós-Graduação em História, com área de concentração em História do Tempo Presente, linha Linguagens e Identificações (2012), bolsista da CAPES; graduação em Moda com Habilitação em Estilismo pela Universidade do Estado de Santa Catarina - UDESC (2011); e graduação em Direto pela Universidade Federal de Santa Catarina - UFSC (2007). 0 presente artigo foi extraído do Trabalho de Conclusão de Curso da autora.

karitha23@yahoo.com.br 